The Neglected Intelligence Course: Needs and Suggested Solutions

Jared Z. Burton and Russell T. Warne

Utah Valley University

Paper published! Please cite as:

Burton, J. Z., \& Warne, R. T. (2020). The neglected intelligence course: Needs and suggested solutions. Teaching of Psychology, 47(2), 130-140. https://doi.org/10.1177/0098628320901381

Jared Z. Burton, Department of Behavioral Science, Utah Valley University; Russell T. Warne, Department of Behavioral Science, Utah Valley University.

This study was partially funded by a Utah Valley University Grant for Engaged Learning (GEL). Both authors contributed equally to this study. They are listed in alphabetical order by surname. 
Correspondence concerning this article should be addressed to Russell T. Warne, Department of Behavioral Science, Utah Valley University, 800 W. University Parkway MC 115, Orem, UT, 84058. Email: rwarne@uvu.edu

\begin{abstract}
Intelligence is a well-studied construct in psychology that has correlational relationships with many educational, employment, and health outcomes. However, prior research indicates that incorrect beliefs about intelligence are widespread. In an effort to discern the degree to which the psychology curriculum is responsible for these inaccuracies, we collected course descriptions and catalog information from 303 American colleges and universities. We found that college courses dedicated to mainstream intelligence science are rare. Because the lack of intelligence education within psychology is a plausible contributor to incorrect beliefs about intelligence, we present an outline for a college-level course on intelligence. We also provide advice for implementing a course, including course readings and advice for handling controversies.
\end{abstract}


The Neglected Intelligence Course: Needs and Suggested Solutions

Although there is considerable heterogeneity across programs, there are several commonalities to the undergraduate psychology education curriculum. In a recent survey of course catalogs, Stoloff et al. (2010) found that over three-quarters of psychology programs offered courses in research methods, developmental psychology, introductory psychology, abnormal psychology, social psychology, personality psychology, physiological psychology, history and systems, learning and memory, and cognitive psychology. These areas largely match the American Psychological Association's (2014) five “pillars" of psychology that represent the core of the discipline: social/personality, mental and physical health, developmental, cognitive, and biological. However, psychology students generally have a great deal of flexibility in the courses that they must complete to graduate (Stoloff et al., 2010; Stoloff, Good, Smith, \& Brewster, 2015). Many students have the option to take courses in niche areas of psychology, such as child psychopathology, drugs and behavior, and behavior modification.

While we are pleased with the breadth and flexibility of psychology education, we believe there is a major gap in the psychology curriculum: a course on intelligence, which one expert called "... one of the scientifically most productive constructs in psychology ..." (Jensen, 2002, p. 150) and yet, it is rarely the subject of a dedicated course in psychology departments. Given that “... intelligence ranks among the best understood psychological constructs ..." (Warne, 2016, p. 5), we believe that the consequences of this lacuna in the psychology curriculum have been distinctly negative and that psychology faculty should add an intelligence course to their curriculum.

\section{What Is Intelligence?}


Although — like many constructs in psychology — there is disagreement about an exact definition of intelligence, one definition has found widespread support, which states that, Intelligence is a very general mental capability that, among other things, involves the ability to reason, plan, solve problems, think abstractly, comprehend complex ideas, learn quickly and learn from experience. It is not merely book learning, a narrow academic skill, or test-taking smarts. Rather, it reflects a broader and deeper capability for comprehending our surroundings — "catching on," "making sense" of things, or "figuring out" what to do. (Gottfredson, 1997a, p. 13).

This definition is often operationalized via scores (commonly called IQ scores) on intelligence tests. These scores correlate with a wide variety of educational, occupational, health, and life outcomes (Jensen, 1998; Lubinski, 2000; Warne, 2016). These include a positive correlation with income (Lubinski, Benbow, \& Kell, 2014; Nyborg \& Jensen, 2001; Strenze, 2007), job prestige (Gottfredson, 1997b; Nyborg \& Jensen, 2001), longevity (Arden et al., 2016; Čukić, Brett, Calvin, Batty, \& Deary, 2017), good mental health (Deary, Whiteman, Starr, Whalley, \& Fox, 2004), functional independence in old age (Deary et al., 2004), and offspring's intelligence (Bouchard \& McGue, 1981). On the other hand, IQ scores correlate negatively with criminal behavior (Beaver et al., 2013), divorce (Gottfredson, 1997b), dementia (Deary et al., 2014), and more. There is no other psychological variable that correlates with so many variables that are important to people's lives.

Yet, the evidence indicates that psychology students learn little about intelligence in their education. In three different studies analyzing the psychology undergraduate curriculum, researchers found that courses in intelligence were not available to students at all (Perlman \& McCann, 1999, 2005; Stoloff et al., 2010). However, many students are introduced to the 
concept of intelligence in their introductory psychology courses, as demonstrated by the fact that every introductory psychology textbook discusses the topic (Griggs, 2014; Warne, Astle, \& Hill, 2018). This information, though, is often superficial and distorted; Warne et al. (2018) found that over 3/4 of textbooks contained basic factual errors about intelligence.

Our opinion is that psychology has abdicated its duty to educate its students about intelligence and intelligence research. As a result, there is widespread ignorance about the construct, and empirically weak ideas have filled the vacuum. As evidence of this thesis, we present data from a search for intelligence courses in the course catalogs at 303 universities. Then, we conclude by presenting an example intelligence course and providing guidance to readers who are interested in offering an intelligence course at their institutions.

\section{Study of Course Catalogs}

There are several theories prevalent among non-experts that are not empirically supported, such as emotional intelligence and multiple intelligences. (See Brody, 2004; Castejon, Perez, \& Gilar, 2010; Locke, 2005; van der Linden et al., 2017; Waterhouse, 2006; for robust, empirically-based criticisms of these theories.) Therefore, it is important to consider how these theories become widespread. Researchers who have investigated the undergraduate psychology curriculum (Perlman \& McCann, 1999, 2005; Stoloff et al., 2010) indicated that few of psychology departments include courses dedicated to intelligence. Consequently, we sought to examine the place of intelligence theories in the university curriculum as a whole.

As there is no previous research containing data on intelligence courses in colleges, we engaged in an exploratory analysis without conducting any specific statistical tests. Moreover, because there are numerous methods by which one may approach analyzing these data, we believed that using null hypothesis tests would encourage selective reporting and distort our 
interpretation of our data. Instead, we searched university course catalogs to understand the frequency and nature by which intelligence is taught across all the different fields of study in American universities.

\section{Methods}

Our sample of universities for our study of course catalogs was taken from the U.S. News and World Report university rankings (available from https://www.usnews.com/bestcolleges/rankings/national-universities), which provide a list of the top 100 national universities, top 25 universities in the North, South, Midwest, and West regions, and the top 100 liberal arts universities in the United States. Because there were some ties for the bottom rank in each list, we collected data from a total of 303 different universities. We used these rankings because it created a more objective variable by which to sample universities, and we believed that the equal combination of top competitive universities, regionally-based universities, and the more narrowfocused liberal arts colleges would properly represent the diverse colleges and universities across the country.

We searched each university's catalog for courses containing the word "intelligence" in the course title or description. However, we excluded a priori classes in business intelligence and military intelligence. When we encountered course descriptions that used intelligence as an adjective (e.g., "she spoke with intelligence"), we excluded these as well. Finally, we decided that artificial intelligence classes were appropriate if comparisons were explicitly made to human intelligence, such as a cognitive science class with information processing components. But we did not include artificial intelligence courses that took a perspective based purely in computer science (e.g., machine learning). 
We recorded whether courses were fully dedicated to intelligence or whether intelligence was mentioned as a component of the course. A class was only considered to be fully dedicated to intelligence if its title and description refer only to intelligence and its correlates (e.g., a course on "Intelligence and Creativity" would be considered fully dedicated). The courses were categorized further by the following characteristics:

1. Focusing on emotional intelligence,

2. Focusing on social intelligence,

3. Focusing on cultural intelligence,

4. Focusing on multiple intelligences (i.e., Howard Gardner's theory),

5. Focusing on artificial intelligence (including relationships with human cognition and intelligence),

6. Focusing on animal intelligence,

7. Courses on testing and psychometrics,

8. Focusing on $g$ theories of intelligence,

9. Introductory psychology courses,

10. Focusing on intelligence and race (including courses mentioning intelligence in the context of eugenics or group relations),

11. Generic or unspecified use of the term "intelligence."

It is important to note that classes could belong to multiple categories, as it is plausible that a class might explicitly mention multiple theories. Finally, we labelled each course as being undergraduate or graduate level.

We formatted the descriptive statistics in several different ways, primarily by course department, intelligence type (from the list above), university type, graduate and undergraduate 
status, and whether the class was wholly dedicated to intelligence. Our Open Science Framework web page (https://osf.io/fvc97/) contains the dataset, and supplemental materials, including all raw data, re-formatted tables, as well as lists of the web links used to search each university.

\section{Results}

Descriptive statistics for course catalog data are available in multiple formats in Tables 1 to 5, as well as in the appendix. As shown in Table 1, 387 (43.3\%) of the 893 courses belonged to the psychology department. However, these classes were overwhelmingly psychometrics courses, introductory courses, or labelled as generic (e.g., developmental psychology courses that refer to intelligence in the context of cognitive changes in aging). Psychology courses accounted for 9 out of the 12 courses that explicitly include mainstream $g$ theory in its description. Of the other 3 courses, 2 belonged to the other social sciences and were specifically focused on how intelligence relates to racial issues, and the other is a philosophy course. Out of those 9 psychology courses, 3 are only available at the graduate level.

\section{INSERT TABLE 1 ABOUT HERE.}

The next largest category of courses included business, management, leadership, and personal development courses, which has 188 (21.1\%) courses. Of these courses, all but 14 of them included references to the theory of multiple intelligences or emotional, cultural, or social intelligence. None of the others referenced $g$ theory, and most were generic or other less common intelligence theories (e.g., appreciative, creative, and innovative intelligences). Of the other nonspecific courses, one was a study abroad experience that included a reference to animal intelligence, and another was a leadership camp that tests intelligence in an undisclosed manner. As noted in Table 2, this grouping of business-oriented courses was responsible for $75.9 \%$ of 
emotional intelligence classes, $53.3 \%$ of social intelligence classes, and $81.0 \%$ of cultural intelligence classes.

\section{INSERT TABLE 2 ABOUT HERE.}

Education courses, which accounted for $15.0 \%(n=134)$ of courses included in the data set, were the third largest group. Two-thirds of all classes teaching multiple intelligences were in education, though most education courses were either generic $(n=57)$ or related to testing and psychometrics $(n=40)$. There were, however, no education courses that explicitly mentioned mainstream $g$-related intelligence theories.

\section{INSERT TABLE 3 ABOUT HERE.}

Most courses $(n=765 ; 85.6 \%$ ) were not principally dedicated to intelligence, and only mentioned it briefly in the description. Out of the courses that were dedicated to intelligence, there were six times $(n=36)$ more courses dedicated to emotional intelligence than those dedicated to $g$ theories of intelligence $(n=4)$. Similarly, of courses where intelligence was only mentioned, there were nearly 20 times $(n=159)$ more courses including emotional intelligence than those explicitly mentioning $g(n=8)$.

\section{INSERT TABLE 4 ABOUT HERE.}

Table 4 indicates the types of courses available at the graduate and undergraduate level. Graduate programs had fewer courses available $(n=295)$ than undergraduate programs, but the classes were distributed across the categories relatively similarly to undergraduate courses. One notable exception was graduate courses mentioning intelligence testing, which accounted for $58.0 \%(n=116)$ of all courses of that type.

\section{Discussion}


Overall, not only did we not expect so few classes $(n=12$, with only 3 being fully dedicated psychology courses) explicitly directed at teaching mainstream intelligence theory, we also did not anticipate so many classes teaching unscientific theories of intelligence (emotional, social, cultural, and/or multiple intelligences are taught in 271 , or $30.3 \%$, of courses). A total of $28.4 \%$ of courses did not have a specific labelling, and if those classes were to follow the same trend as the rest of the data, there would still be a very small percentage of total courses that teach mainstream, empirically supported theories of intelligence. Non-psychology departments, in particular, appear to be more likely than others to teach empirically weak intelligence theories. Emotional intelligence was largely contained within the business, leadership, management, and personal development courses. Multiple intelligences theory was most notable within education courses. We find this latter fact disturbing because intelligence is one of the best predictors of educational success at the individual level (Cucina, Peyton, Su, \& Byle, 2016; Gottfredson, 1997b), and yet future teachers — if they learn about intelligence at all — are largely taught about Howard Gardner's empirically unsupported theory of multiple intelligences. Although we do not know how this impacts educational practice, it does not bode well because interventions based on correct theories are more likely to succeed than interventions based on incorrect beliefs about reality.

Given the poor support for non- $g$ theories of intelligence, we are disappointed that these theories are so commonly taught in applied areas of business and education. Teaching incorrect theories may lead future practitioners astray in their work. Business leaders, for example, may select employees for promotion or in hiring who excel in "emotional intelligence" instead of general intelligence, even though the latter is a better predictor of job success (Pesta, McDaniel, Poznanski, \& DeGroot, 2015). Teachers who subscribe to multiple intelligences theory may 
engage in fruitless efforts to educate all of the "intelligences" in the theory or to seek ways to teach students that align with their supposed strengths.

Collecting data from course catalogs has a few limitations. Catalogs are not standardized, and some universities provided much more information regarding their courses than others. Consequently, it is possible that some instructors teach about intelligence, even though the topic is not mentioned in the catalog. In addition, the groupings created to categorize courses introduce some subjectivity. For example, we listed courses that mention artificial intelligence only if they explicitly mentioned its relationship to human intelligence. Yet, there were some cognitive science courses that were excluded because the catalog did not explicitly mention human intelligence, even though the topic could have naturally fit in with the course content.

Intelligence categories were also subject to interpretation, as many of the references to intelligence were vague or broad in nature. Often course descriptions do not provide enough information to classify a course beyond the generic/unspecified category. Moreover, course descriptions are not detailed enough to justify conclusions about how intelligence is taught or whether different theories are empirically evaluated in individual classrooms. For example, it is likely that a psychometrics course that includes a unit on intelligence testing would inform students of the mainstream theory of intelligence that provides a theoretical foundation and interpretive framework for intelligence tests. However, this information regarding this theoretical and empirical context for interpreting intelligence tests would not appear in a course catalog. Even so, $58.0 \%$ of psychometric courses were at the graduate level, and were not courses available to the large number of students enrolled in undergraduate psychology majors.

Additionally, there was some inconsistency in the ability to query the catalogs. Some universities do not post pdf versions of course catalogs online, and the class search functions 
only searched through available courses in a particular semester. In these cases, we typically searched through two years of scheduled courses. However, with 893 different courses collected from 303 universities, we believe that the dataset is robust and fairly represents the ways intelligence is taught at institutions of higher education in the United States.

\section{Example Course on Intelligence}

The information we present in our analysis of university course catalogs shows that incorrect ideas about intelligence are frequently taught. We believe that adding a course dedicated to the study of intelligence would strengthen psychology education. In this section of the article, we provide information about our institution's undergraduate course on intelligence and some practical guidelines in the hopes that our experience can help faculty at other institutions plug this hole in the curriculum.

Other intelligence experts have offered advice about creating an intelligence course (e.g., Brody, 2014; Deary, 2014; Detterman, 2014; Haier, 2014; Hunt, 2014; Mackintosh, 2014), and we encourage readers to consult these articles. However, when the second author began the process of creating an intelligence course, he found that these sources were excellent for providing general guidelines, but that specific suggestions were often lacking. Our goal in this section is to provide guidance about issues that may arise in designing and/or teaching an intelligence course.

The first (and sometimes most daunting) task that an instructor has when planning an intelligence course is deciding what to include in the curriculum. Haier (2014) has the most detailed course outline in the published literature, and most of his 18 units will comfortably fit into any intelligence course. Mackintosh (2014) and Detterman (2014) also provided a list of course topics and their sequence, though with less detail than Haier (2014). We encourage 
readers to consult these outlines. The course that one of us (the second author) teaches follows the sequence in Table 5. The outline in Table 5 is for a 12-week course, which is shorter than most semesters; the extra time is useful for test days and to expand units related to concepts that an instructor finds important. The lessons that we believe are most important are marked in bold and include foundational topics (e.g., an introduction to $g$, intelligence testing), the biological basis of intelligence (i.e., intelligence and the brain, genetics), related topics from cognitive psychology, and the social impact of intelligence differences in education, work, and health. These units are the core topics because they explain what intelligence is, how it is measured, how it arises in the brain, and why intelligence is important. Any course that does not include these units would have fundamental deficiencies that would prevent students from having a comprehensive understanding of intelligence.

\section{INSERT TABLE 5 ABOUT HERE.}

Table 5 should not be considered the only viable curriculum for teaching intelligence. It is suited to the second author's expertise and the textbook (Hunt, 2011) used in the undergraduate class. Students could benefit from an expansion of some topics, and an instructor may wish to eliminate some of the less essential topics, such as the discussion of aging. A class session or two on methodology (especially to refresh students' knowledge of correlations or to introduce them to factor analysis) may also be a fruitful use of class time. Class units in animal intelligence, longitudinal studies, cognitive development in childhood, evolutionary psychology and intelligence, and other topics may be interesting to students. Student interest may be a particularly important driver of the curriculum at the graduate level, where specialization of study may make our generalist course outline less useful. 
The final two units in Table 5 encourage critical thinking and dealing with conflicting societal goals and ambiguous evidence. The unit entitled "logical fallacies used to dismiss intelligence research" is based on a book chapter by Gottfredson (2009) and includes an activity where students watch a video (Hermann \& Bentura, 2010) and attempt to identify these fallacies in use. The last unit, societal impacts of intelligence, is an open-ended discussion of how intelligence can inform current political events. As such, the lesson content changes each semester, but the two overall messages from the unit stay the same. The first message is that intelligence has important impacts on society. The second message from the unit is that the scientific facts are value neutral and can support multiple social, political, and ethical goals. In addition to the Hunt (2011) book, Mackintosh (2011) wrote another viable textbook for this course. Both are suitable for students in their final two years of undergraduate education or the early years of their graduate studies. Supplemental articles could be useful readings, especially classic articles by Gottfredson (1997a, 1997b), Flynn, (1987), Murray (2002), and Neisser et al. (1996). Many articles published in the journal Intelligence are accessible to undergraduate students because the methodologies are inherently based on correlations and the writing style in the journal tends to be crisp and direct. Instructors who prefer a more biologically oriented course will find Haier's (2017) The Neuroscience of Intelligence to be a useful text for undergraduate or graduate students, and Jung and Haier's (2007) landmark article in the parieto-frontal integration theory of intelligence and the response articles would provide plenty of fodder for discussion for graduate students in neuroscience or biopsychology programs. For a lower-division undergraduate or high school course, we recommend Ritchie's (2015) and Deary's (2001) basic introductions to intelligence. 
A course on intelligence provides many opportunities for assignments that apply students' new knowledge. The second author's course includes writing assignments where students summarize and respond to a scholarly article. The final project in the course is also a paper in which students write about a topic of their own choosing from the 100 listed in Table 6. All of these topics have sufficient research that a student could easily find several scholarly articles as sources for an informative paper about the topic. The second author also administers three tests and a number of surprise reading quizzes during the course of the semester.

\section{INSERT TABLE 6 ABOUT HERE.}

Other activities can help students master important course concepts. Standard laboratory procedures to examine working memory may be useful when discussing the connections between intelligence research and cognitive psychology. Sample intelligence test items, like digit span or mental rotation tasks, are helpful in making intelligence test content less abstract, and we have had success in creating materials (available at [HYPERLINK BLINDED]) that allow students to take the World War I-era Army Beta intelligence test. This latter activity gives students insight into early test development and test items that have reduced language demands. Recordings of television quiz shows can help students classify questions into measuring fluid intelligence or crystallized intelligence. Because intelligence research touches on so many areas of psychology, activities from other courses-especially cognitive psychology, psychometrics, and educational psychology-can help students understand intelligence.

One particular topic deserves frank discussion because of the disproportionate attention that it receives: demographic group differences in intelligence (especially racial/ethnic group differences). In the course that we have experience with, the topic is one of the last in the semester, mostly because we do not believe that it is the most important topic related to 
intelligence and that foundational ideas emphasized in Table 5 should receive attention first. However, the lesson is carefully structured to reduce the chances of misunderstandings and to emphasize that the data are often unclear and contradictory. When the course started at our institution, the instructor also worked with the then-president of the Black Student Union (a psychology student) to create "ground rules" that governed discussing controversial topics in class without censoring ideas or restricting academic freedom. These were

1. All human beings are entitled to dignity and human rights.

2. Mean group differences do not justify discriminatory behavior.

3. Discussing mean group differences in abilities is not discriminatory.

4. Even though mean differences exist across groups, there is still a lot of overlap across groups.

5. All possible explanations for causes of mean group differences should be explored.

6. It is not bigoted to discuss mean group differences or their causes.

7. Americans have a history of progress towards fairness, openness, and tolerance. This nation should maintain those efforts.

8. All students are welcome to voice concerns about these issues.

Ensuring that every student understands and abides by these rules has been helpful in allowing students with a variety of cultural backgrounds and political beliefs to feel safe in the classroom, even when discussing uncomfortable topics. How one chooses to handle this sensitive topic will vary, according to the student body and institutional climate. Brody (2014) and Hunt (2014) believed that the topic should be discussed frankly and empirically. Mackintosh (2014) preferred to discuss demographic group differences in intelligence early in the course. We understand, though, if an instructor drops this topic from the curriculum, which Warne et al. (2018) stated 
was a viable strategy for handling the discussion of mean group differences in an introductory psychology textbook discussion of intelligence.

Regardless of the exact curriculum of an intelligence course, we believe that any course is better than the status quo at most universities, which is a haphazard mentions of intelligence in tangentially related courses and no dedicated course on the topic. Given that most introductory textbooks in psychology contain basic errors about intelligence (Warne et al., 2018), a course based on strong theory and the research that has accumulated for over a century would clarify misconceptions that many psychology students have. We believe that the degree of neglect of intelligence in the psychology curriculum is a travesty, and implementing even some of our recommendations would be a step in the right direction of filling the gap in the psychology curriculum.

\section{Conclusion}

Intelligence is a vitally important concept, from both a scientific and a practical perspective. In this article, we showed inaccurate viewpoints about intelligence pervade American university course catalogs and that most psychology programs do not have a systematic way of teaching about intelligence. Dedicated courses on the topic are rare, and courses on multiple intelligences, emotional intelligence, and other empirically weak ideas are much more common. In an attempt to help psychology instructors fill this gap in their curriculum, we have provided an outline from our university's dedicated intelligence course. We have also addressed issues related to course readings, activities, and how to handle controversies related to intelligence.

Although changes to the undergraduate psychology curriculum are slow, we are optimistic that future years could see a course on intelligence become more common. If our 
hopes are fulfilled, then we expect that there would be an increased understanding of intelligence research in the psychology community. 


\section{References}

American Psychological Association. (2014). Strengthening the common core of the introductory psychology course. Washington, DC: American Psychological Association, Board of Educational Affairs. Retrieved from http://www.apa.org/ed/governance/bea/intro-psychreport.pdf

Arden, R., Luciano, M., Deary, I. J., Reynolds, C. A., Pedersen, N. L., Plassman, B. L., . . . Visscher, P. M. (2016). The association between intelligence and lifespan is mostly genetic. International Journal of Epidemiology, 45, 178-185. doi:10.1093/ije/dyv112

Beaver, K. M., Schwartz, J. A., Nedelec, J. L., Connolly, E. J., Boutwell, B. B., \& Barnes, J. C. (2013). Intelligence is associated with criminal justice processing: Arrest through incarceration. Intelligence, 41, 277-288. doi:10.1016/j.intell.2013.05.001

Bouchard, T. J., \& McGue, M. (1981). Familial studies of intelligence: A review. Science, 212, 1055-1059. doi:10.1126/science.7195071

Brody, N. (2004). What cognitive intelligence is and what emotional intelligence is not. Psychological Inquiry, 15, 234-238.

Brody, N. (2014). A plea for the teaching of intelligence: Personal reflections. Intelligence, 42, 136-141. doi:10.1016/j.intell.2013.08.005

Castejon, J. L., Perez, A. M., \& Gilar, R. (2010). Confirmatory factor analysis of Project Spectrum activities. A second-order $g$ factor or multiple intelligences? Intelligence, 38, 481-496. doi:10.1016/j.intell.2010.07.002

Cucina, J. M., Peyton, S. T., Su, C., \& Byle, K. A. (2016). Role of mental abilities and mental tests in explaining high-school grades. Intelligence, 54, 90-104. doi:10.1016/j.intell.2015.11.007 
Čukić, I., Brett, C. E., Calvin, C. M., Batty, G. D., \& Deary, I. J. (2017). Childhood IQ and survival to 79: Follow-up of $94 \%$ of the Scottish Mental Survey 1947. Intelligence, 63, 45-50. doi:10.1016/j.intell.2017.05.002

Deary, I. J. (2001). Human intelligence differences: A recent history. Trends in Cognitive Sciences, 5, 127-130. doi:10.1016/s1364-6613(00)01621-1

Deary, I. J. (2014). Teaching intelligence. Intelligence, 42, 142-147. doi:10.1016/j.intell.2013.07.002

Deary, I. J., Whiteman, M. C., Starr, J. M., Whalley, L. J., \& Fox, H. C. (2004). The impact of childhood intelligence on later life: Following up the Scottish Mental Surveys of 1932 and 1947. Journal of Personality and Social Psychology, 86, 130-147. doi:10.1037/00223514.86.1.130

Detterman, D. K. (2014). You should be teaching intelligence! Intelligence, 42, 148-151. doi:10.1016/j.intell.2013.07.021

Flynn, J. R. (1987). Massive IQ gains in 14 nations: What IQ tests really measure. Psychological Bulletin, 101, 171-191. doi:10.1037/h0090408

Gottfredson, L. S. (1997a). Mainstream science on intelligence: An editorial with 52 signatories, history, and bibliography. Intelligence, 24, 13-23. doi:10.1016/S0160-2896(97)90011-8

Gottfredson, L. S. (1997b). Why g matters: The complexity of everyday life. Intelligence, 24, 79132. doi:10.1016/S0160-2896(97)90014-3

Gottfredson, L. S. (2009). Logical fallacies used to dismiss the evidence on intelligence testing. In R. P. Phelps (Ed.), Correcting fallacies about educational and psychological testing (pp. 11-65). Washington, DC: American Psychological Association. 
Griggs, R. A. (2014). Topical coverage in introductory textbooks from the 1980s through the 2000s. Teaching of Psychology, 41, 5-10. doi:10.1177/0098628313514171

Haier, R. J. (2014). The universe, dark matter, and streaming intelligence. Intelligence, 42, 152155. doi:10.1016/j.intel.2013.07.022

Haier, R. J. (2017). The neuroscience of intelligence. New York, NY: Cambridge University Press.

Hermann, L. (Producer), \& Bentura, S. (Director). (2010). IQ: A history of deceit [Motion picture]. France: Premières Lignes Télévision.

Hunt, E. (2011). Human intelligence. New York, NY: Cambridge University Press.

Hunt, E. (2014). Teaching intelligence: Why, why it is hard and perhaps how to do it. Intelligence, 42, 156-165. doi:10.1016/j.intell.2013.06.018

Jensen, A. R. (1998). The g factor: The science of mental ability. Westport, CT: Praeger.

Jensen, A. R. (2002). Galton's legacy to research on intelligence. Journal of Biosocial Science, 34, 145-172. doi:10.1017/S0021932002001451

Jung, R. E., \& Haier, R. J. (2007). The Parieto-Frontal Integration Theory (P-FIT) of intelligence: Converging neuroimaging evidence. Behavioral and Brain Sciences, 30, 135-154. doi:10.1017/S0140525X07001185

Locke, E. A. (2005). Why emotional intelligence is an invalid concept. Journal of Organizational Behavior, 26, 425-431. doi:10.1002/job.318

Lubinski, D. (2000). Scientific and social significance of assessing individual differences: "Sinking shafts at a few critical points." Annual Review of Psychology, 51, 405-444. doi:10.1146/annurev.psych.51.1.405 
Lubinski, D., Benbow, C. P., \& Kell, H. J. (2014). Life paths and accomplishments of mathematically precocious males and females four decades later. Psychological Science, 25, 2217-2232. doi:10.1177/0956797614551371

Mackintosh, N. J. (2011). IQ and human intelligence (2nd ed.). New York, NY: Oxford University Press.

Mackintosh, N. J. (2014). Why teach intelligence? Intelligence, 42, 166-170. doi:10.1016/j.intell.2013.08.001

Murray, C. (2002). IQ and income inequality in a sample of sibling pairs from advantaged family backgrounds. American Economic Review, 92(2), 339-343. doi:10.1257/000282802320191570

Neisser, U., Boodoo, G., Bouchard, T. J., Boykin, A. W., Brody, N., Ceci, S. J., . . Urbina, S. (1996). Intelligence: Knowns and unknowns. American Psychologist, 51, 77-101. doi:10.1037/0003-066X.51.2.77

Nyborg, H., \& Jensen, A. R. (2001). Occupation and income related to psychometric $g$. Intelligence, 29, 45-55. doi:10.1016/S0160-2896(00)00042-8

Perlman, B., \& McCann, L. I. (1999). The most frequently listed courses in the undergraduate psychology curriculum. Teaching of Psychology, 26, 177-182. doi:10.1207/S15328023TOP260303

Perlman, B., \& McCann, L. I. (2005). Undergraduate research experiences in psychology: A national study of courses and curricula. Teaching of Psychology, 32, 5-14. doi:10.1207/s15328023top3201_2 
Pesta, B. J., McDaniel, M. A., Poznanski, P. J., \& DeGroot, T. (2015). Discounting IQ’s relevance to organizational behavior: The "somebody else's problem" in management education. Open Differential Psychology, 35, 1-11.

Ritchie, S. (2015). Intelligence: All that matters. London, UK: John Murray Learning.

Stoloff, M., McCarthy, M., Keller, L., Varfolomeeva, V., Lynch, J., Makara, K., . . Smiley, W. (2010). The undergraduate psychology major: An examination of structure and sequence. Teaching of Psychology, 37, 4-15. doi:10.1080/00986280903426274

Stoloff, M. L., Good, M. R., Smith, K. L., \& Brewster, J. (2015). Characteristics of programs that maximize psychology major success. Teaching of Psychology, 42, 99-108. doi:10.1177/0098628315569877

Strenze, T. (2007). Intelligence and socioeconomic success: A meta-analytic review of longitudinal research. Intelligence, 35, 401-426. doi:10.1016/j.intell.2006.09.004 van der Linden, D., Pekaar, K. A., Bakker, A. B., Schermer, J. A., Vernon, P. A., Dunkel, C. S., \& Petrides, K. V. (2017). Overlap between the general factor of personality and emotional intelligence: A meta-analysis. Psychological Bulletin, 143, 36-52. doi:10.1037/bul0000078

Warne, R. T. (2016). Five reasons to put the $g$ back into giftedness: An argument for applying the Cattell-Horn-Carroll theory of intelligence to gifted education research and practice. Gifted Child Quarterly, 60, 3-15. doi:10.1177/0016986215605360

Warne, R. T., Astle, M. C., \& Hill, J. C. (2018). What do undergraduates learn about human intelligence? An analysis of introductory psychology textbooks. Archives of Scientific Psychology, 6, 32-50. doi:10.1037/arc0000038 
Waterhouse, L. (2006). Multiple intelligences, the Mozart effect, and emotional intelligence: A critical review. Educational Psychologist, 41, 207-225. doi:10.1207/s15326985ep4104_1 
Table 1

Catalog: Frequency of Courses by Subject Department

\begin{tabular}{|c|c|c|c|c|}
\hline Department & Courses & $\begin{array}{c}\text { Courses } \\
\text { (Cross Listed) }\end{array}$ & Total Courses & ${ }^{\text {apercentage }}$ \\
\hline Psychology & 387 & 6 & 393 & $43.3 \%$ \\
\hline $\begin{array}{l}\text { Business, management, } \\
\text { leadership \& personal }\end{array}$ & 188 & 2 & 190 & \\
\hline development & & & & $21.1 \%$ \\
\hline Education & 134 & 21 & 155 & $15.0 \%$ \\
\hline Humanities & 44 & 3 & 47 & $4.9 \%$ \\
\hline Computer & 23 & 0 & 23 & \\
\hline science/engineering & & & & $2.6 \%$ \\
\hline Cognitive science & 21 & 1 & 22 & $2.4 \%$ \\
\hline Philosophy & 19 & 1 & 20 & $2.1 \%$ \\
\hline Health/medicine & 14 & 0 & 14 & $1.6 \%$ \\
\hline Anthropology & 13 & 0 & 13 & $1.5 \%$ \\
\hline Biology & 12 & 1 & 13 & $1.3 \%$ \\
\hline Arts & 11 & 0 & 11 & $1.2 \%$ \\
\hline Genetics/evolution & 7 & 10 & 17 & $0.8 \%$ \\
\hline Social science & 4 & 1 & 5 & $0.4 \%$ \\
\hline Religion & 4 & 0 & 4 & $0.4 \%$ \\
\hline Neuroscience & 4 & 3 & 7 & $0.4 \%$ \\
\hline English & 4 & 0 & 4 & $0.4 \%$ \\
\hline Other & 2 & 0 & 2 & $0.2 \%$ \\
\hline Sociology & 1 & 0 & 1 & $0.1 \%$ \\
\hline Family studies & 1 & 0 & 1 & $0.1 \%$ \\
\hline Total & 893 & 49 & 942 & $100.00 \%$ \\
\hline
\end{tabular}

Note. Some courses were cross-listed or were part of specialized departments. In these cases,

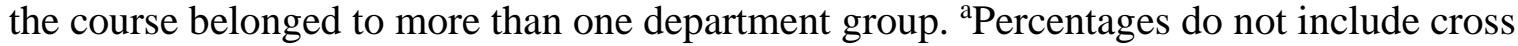
listed courses. 
Table 2

Catalog: Frequencies and Percentages of Courses Based on Department Grouping and Intelligence Categories

\begin{tabular}{|c|c|c|c|c|c|c|c|c|c|c|c|c|c|}
\hline Department & Graduate & $\begin{array}{c}\text { Emotiona } \\
1 \\
\end{array}$ & Social & Cultural & Multiple & Generic & $\begin{array}{c}g \\
\text { Theories } \\
\end{array}$ & $\begin{array}{l}\text { Introductory } \\
\text { Psychology }\end{array}$ & Testing & Race & Artificial & Animal & Other \\
\hline Psychology & $\begin{array}{c}133 \\
(24.9 \%)\end{array}$ & $14(2.6 \%)$ & $2(0.4 \%)$ & $0(0.0 \%)$ & $3(0.6 \%)$ & $\begin{array}{c}139 \\
(26.0 \%)\end{array}$ & $9(1.7 \%)$ & $39(7.3 \%)$ & $\begin{array}{c}166 \\
(31.0 \%)\end{array}$ & $\begin{array}{c}6 \\
(1.1 \%)\end{array}$ & $14(2.6 \%)$ & $7(1.3 \%)$ & $3(0.6 \%)$ \\
\hline $\begin{array}{l}\text { Business, } \\
\text { management, } \\
\text { leadership \& } \\
\text { personal } \\
\text { development }\end{array}$ & $76(14.2 \%)$ & $\begin{array}{c}151 \\
(28.2 \%)\end{array}$ & $\begin{array}{c}16 \\
(3.0 \%)\end{array}$ & $\begin{array}{c}17 \\
(3.2 \%)\end{array}$ & $4(0.7 \%)$ & $6(1.1 \%)$ & $0(0.0 \%)$ & $0(0.0 \%)$ & $0(0.0 \%)$ & $\begin{array}{c}0 \\
(0.0 \%)\end{array}$ & $0(0.0 \%)$ & $1(0.2 \%)$ & $7(1.3 \%)$ \\
\hline Education & $72(13.5 \%)$ & $13(2.4 \%)$ & $3(0.6 \%)$ & $1(0.2 \%)$ & $\begin{array}{c}36 \\
(6.7 \%)\end{array}$ & $\begin{array}{c}57 \\
(10.7 \%)\end{array}$ & $0(0.0 \%)$ & $0(0.0 \%)$ & $40(7.5 \%)$ & $\begin{array}{c}3 \\
(0.6 \%)\end{array}$ & $0(0.0 \%)$ & $0(0.0 \%)$ & $2(0.4 \%)$ \\
\hline Humanities & $6(1.1 \%)$ & $3(0.6 \%)$ & $1(0.2 \%)$ & $2(0.4 \%)$ & $2(0.4 \%)$ & $\begin{array}{c}16 \\
(3.0 \%)\end{array}$ & $1(0.2 \%)$ & $0(0.0 \%)$ & $5(0.9 \%)$ & $\begin{array}{c}5 \\
(0.9 \%)\end{array}$ & $10(1.9 \%)$ & $1(0.2 \%)$ & $3(0.6 \%)$ \\
\hline Cognitive science & $6(1.1 \%)$ & $0(0.0 \%)$ & $0(0.0 \%)$ & $0(0.0 \%)$ & $0(0.0 \%)$ & $6(1.1 \%)$ & $0(0.0 \%)$ & $0(0.0 \%)$ & $0(0.0 \%)$ & $\begin{array}{c}0 \\
(0.0 \%)\end{array}$ & $16(3.0 \%)$ & $0(0.0 \%)$ & $0(0.0 \%)$ \\
\hline $\begin{array}{l}\text { Computer science \& } \\
\text { engineering }\end{array}$ & $3(0.6 \%)$ & $5(0.9 \%)$ & $0(0.0 \%)$ & $0(0.0 \%)$ & $0(0.0 \%)$ & $1(0.2 \%)$ & $0(0.0 \%)$ & $0(0.0 \%)$ & $0(0.0 \%)$ & $\begin{array}{c}0 \\
(0.0 \%)\end{array}$ & $16(3.0 \%)$ & $0(0.0 \%)$ & $0(0.0 \%)$ \\
\hline Health/medicine & $6(1.1 \%)$ & $7(1.3 \%)$ & $4(0.7 \%)$ & $0(0.0 \%)$ & $1(0.2 \%)$ & $2(0.4 \%)$ & $0(0.0 \%)$ & $0(0.0 \%)$ & $0(0.0 \%)$ & $\begin{array}{c}0 \\
(0.0 \%)\end{array}$ & $0(0.0 \%)$ & $1(0.2 \%)$ & $0(0.0 \%)$ \\
\hline Philosophy & $0(0.0 \%)$ & $1(0.2 \%)$ & $0(0.0 \%)$ & $0(0.0 \%)$ & $2(0.4 \%)$ & $\begin{array}{c}12 \\
(2.2 \%)\end{array}$ & $1(0.2 \%)$ & $0(0.0 \%)$ & $0(0.0 \%)$ & $\begin{array}{c}0 \\
(0.0 \%)\end{array}$ & $4(0.7 \%)$ & $0(0.0 \%)$ & $0(0.0 \%)$ \\
\hline Genetics/evolution & $1(0.2 \%)$ & $0(0.0 \%)$ & $1(0.2 \%)$ & $0(0.0 \%)$ & $0(0.0 \%)$ & $\begin{array}{c}12 \\
(2.2 \%)\end{array}$ & $0(0.0 \%)$ & $0(0.0 \%)$ & $0(0.0 \%)$ & $\begin{array}{c}2 \\
(0.4 \%)\end{array}$ & $0(0.0 \%)$ & $3(0.6 \%)$ & $0(0.0 \%)$ \\
\hline Anthropology & $1(0.2 \%)$ & $0(0.0 \%)$ & $1(0.2 \%)$ & $0(0.0 \%)$ & $0(0.0 \%)$ & $2(0.4 \%)$ & $1(0.2 \%)$ & $0(0.0 \%)$ & $1(0.2 \%)$ & $\begin{array}{c}2 \\
(0.4 \%)\end{array}$ & $0(0.0 \%)$ & $8(1.5 \%)$ & $0(0.0 \%)$ \\
\hline Biology & $2(0.4 \%)$ & $0(0.0 \%)$ & $1(0.2 \%)$ & $0(0.0 \%)$ & $0(0.0 \%)$ & $7(1.3 \%)$ & $0(0.0 \%)$ & $0(0.0 \%)$ & $0(0.0 \%)$ & $\begin{array}{c}2 \\
(0.4 \%)\end{array}$ & $0(0.0 \%)$ & $3(0.6 \%)$ & $0(0.0 \%)$ \\
\hline Arts & $3(0.6 \%)$ & $0(0.0 \%)$ & $0(0.0 \%)$ & $0(0.0 \%)$ & $5(0.9 \%)$ & $1(0.2 \%)$ & $0(0.0 \%)$ & $0(0.0 \%)$ & $0(0.0 \%)$ & $\begin{array}{c}0 \\
(0.0 \%)\end{array}$ & $0(0.0 \%)$ & $0(0.0 \%)$ & $3(0.6 \%)$ \\
\hline Neuroscience & $1(0.2 \%)$ & $1(0.2 \%)$ & $1(0.2 \%)$ & $0(0.0 \%)$ & $0(0.0 \%)$ & $2(0.4 \%)$ & $1(0.2 \%)$ & $0(0.0 \%)$ & $0(0.0 \%)$ & $\begin{array}{c}1 \\
(0.2 \%)\end{array}$ & $1(0.2 \%)$ & $1(0.2 \%)$ & $0(0.0 \%)$ \\
\hline English & $0(0.0 \%)$ & $1(0.2 \%)$ & $0(0.0 \%)$ & $0(0.0 \%)$ & $1(0.2 \%)$ & $0(0.0 \%)$ & $0(0.0 \%)$ & $0(0.0 \%)$ & $0(0.0 \%)$ & $\begin{array}{c}0 \\
(0.0 \%)\end{array}$ & $1(0.2 \%)$ & $2(0.4 \%)$ & $1(0.2 \%)$ \\
\hline Social science & $0(0.0 \%)$ & $1(0.2 \%)$ & $0(0.0 \%)$ & $0(0.0 \%)$ & $0(0.0 \%)$ & $2(0.4 \%)$ & $0(0.0 \%)$ & $1(0.2 \%)$ & $0(0.0 \%)$ & $\begin{array}{c}0 \\
(0.0 \%)\end{array}$ & $0(0.0 \%)$ & $0(0.0 \%)$ & $1(0.2 \%)$ \\
\hline Religion & $0(0.0 \%)$ & $2(0.4 \%)$ & $0(0.0 \%)$ & $0(0.0 \%)$ & $0(0.0 \%)$ & $0(0.0 \%)$ & $0(0.0 \%)$ & $0(0.0 \%)$ & $0(0.0 \%)$ & $\begin{array}{c}0 \\
(0.0 \%)\end{array}$ & $0(0.0 \%)$ & $0(0.0 \%)$ & $2(0.4 \%)$ \\
\hline Other & $0(0.0 \%)$ & $0(0.0 \%)$ & $0(0.0 \%)$ & $1(0.2 \%)$ & $0(0.0 \%)$ & $1(0.2 \%)$ & $0(0.0 \%)$ & $0(0.0 \%)$ & $0(0.0 \%)$ & $\begin{array}{c}0 \\
(0.0 \%)\end{array}$ & $0(0.0 \%)$ & $0(0.0 \%)$ & $0(0.0 \%)$ \\
\hline Family studies & $0(0.0 \%)$ & $0(0.0 \%)$ & $0(0.0 \%)$ & $0(0.0 \%)$ & $0(0.0 \%)$ & $1(0.2 \%)$ & $0(0.0 \%)$ & $0(0.0 \%)$ & $0(0.0 \%)$ & $\begin{array}{c}0 \\
(0.0 \%)\end{array}$ & $0(0.0 \%)$ & $0(0.0 \%)$ & $0(0.0 \%)$ \\
\hline
\end{tabular}




\begin{tabular}{|c|c|c|c|c|c|c|c|c|c|c|c|c|c|}
\hline Sociology & $0(0.0 \%)$ & $0(0.0 \%)$ & $0(0.0 \%)$ & $0(0.0 \%)$ & $0(0.0 \%)$ & $0(0.0 \%)$ & $0(0.0 \%)$ & $0(0.0 \%)$ & $0(0.0 \%)$ & $\begin{array}{c}1 \\
(0.2 \%)\end{array}$ & $0(0.0 \%)$ & $0(0.0 \%)$ & $0(0.0 \%)$ \\
\hline Total & 310 & 199 & 30 & 21 & 54 & 268 & 13 & 40 & 212 & 22 & 62 & 27 & 22 \\
\hline
\end{tabular}


Table 3

Catalog: Intelligence Topics Mentioned and Dedicated

\begin{tabular}{lccc}
\hline \multicolumn{1}{c}{ Category } & Mentioned & Dedicated & Total \\
\hline Graduate & 241 & 55 & 296 \\
Generic & 233 & 21 & 254 \\
Testing & 163 & 37 & 200 \\
Emotional & 159 & 36 & 195 \\
Multiple & 44 & 3 & 47 \\
Introductory & 40 & 0 & 40 \\
Social & 20 & 8 & 28 \\
Cultural & 16 & 5 & 21 \\
Race & 18 & 1 & 19 \\
$g$ Theories & 8 & 4 & 12 \\
\hline
\end{tabular}


Table 4

Catalog: Frequencies of Categories Available at the Graduate/Undergraduate Level

\begin{tabular}{cccc}
\hline Intelligence Category & Graduate & Undergraduate & Total \\
\hline Generic & 53 & 201 & 254 \\
g-Theory & 3 & 9 & 12 \\
Emotional & 80 & 115 & 195 \\
Social & 10 & 18 & 28 \\
Cultural & 5 & 16 & 21 \\
Multiple & 17 & 30 & 47 \\
Testing & 116 & 84 & 200 \\
Race & 2 & 17 & 19 \\
Artificial & 8 & 51 & 59 \\
Animal & 1 & 23 & 24 \\
Other & 0 & 19 & 19 \\
\hline Total & 295 & 583 & 878 \\
\hline
\end{tabular}


Table 5

Sample Schedule and Sequence of Topics for an Undergraduate Intelligence Course

\begin{tabular}{|c|c|c|}
\hline Week \# & Session \# & Topic \\
\hline 1 & 1 & Course overview: Definition and nature of intelligence \\
\hline 1 & 2 & Course overview: Reality of intelligence as a construct \\
\hline 1 & 3 & Course overview: Historical and modern context \\
\hline 2 & 4 & Introduction to $g$ \\
\hline 2 & 5 & Intelligence tests: Characteristics of good tests \\
\hline 2 & 6 & Intelligence tests: Common intelligence tests \\
\hline 3 & 7 & Cattell-Horn-Carroll theory of intelligence \\
\hline 3 & 8 & Intelligence and the brain: Brain size and anatomy \\
\hline 3 & 9 & Intelligence and the brain: Parieto-frontal integration theory \\
\hline 4 & 10 & Cognitive processes: Introduction, processing speed \& reaction time \\
\hline 4 & 11 & Cognitive processes: Working memory \\
\hline 4 & 12 & Cognitive processes: Verbal and spatial abilities \\
\hline 5 & 13 & Genetics of intelligence: Background \\
\hline 5 & 14 & Genetics of intelligence: Heritability \\
\hline 5 & 15 & Genetics of intelligence: Abnormalities \\
\hline 6 & 16 & Genetics of intelligence: Normal range of ability \\
\hline 6 & 17 & $\begin{array}{l}\text { Environmental effects on intelligence: Basics and physical } \\
\text { environment }\end{array}$ \\
\hline 6 & 18 & $\begin{array}{l}\text { Environmental effects on intelligence: Home environment \& } \\
\text { interventions }\end{array}$ \\
\hline 7 & 19 & Social impact of intelligence: Education \\
\hline 7 & 20 & Social impact of intelligence: Work \\
\hline 7 & 21 & Social impact of intelligence: Work \\
\hline 8 & 22 & Social impact of intelligence: Everyday life \\
\hline 8 & 23 & Social impact of intelligence: Health \\
\hline 8 & 24 & Social impact of intelligence: Crime and punishment \\
\hline 9 & 25 & Flynn effect \\
\hline 9 & 26 & Intelligence and the aging process: $g$ and global IQ \\
\hline 9 & 27 & $\begin{array}{l}\text { Intelligence and the aging process: Inter-individual variability and } \\
\text { interventions }\end{array}$ \\
\hline 10 & 28 & Sex differences in $g$ and global IQ \\
\hline 10 & 29 & Sex differences in non- $g$ cognitive abilities \\
\hline 10 & 30 & Racial/ethnic group differences in cognitive abilities: Introduction \\
\hline 11 & 31 & Racial/ethnic group differences in cognitive abilities: Size of differences \\
\hline 11 & 32 & $\begin{array}{l}\text { Racial/ethnic group differences in cognitive abilities: Hypothesized } \\
\text { causes }\end{array}$ \\
\hline 11 & 33 & Logical fallacies used to dismiss intelligence research \\
\hline 12 & 34 & Logical fallacies used to dismiss intelligence research \\
\hline 12 & 35 & Societal implications \\
\hline 12 & 36 & Societal implications \\
\hline
\end{tabular}


Table 6

100 Potential Final Paper Topics in an Undergraduate Intelligence Course

Overview

- The Cattell-Horn-Carroll theory of intelligence

- Is $g$ real?

- Differences and similarities in the terms "cognitive abilities," "intelligence," "IQ," and " $g$ "

- Competing theories (any of these could be a could be the topic of a paper)

○ Sternberg's triarchic theory of intelligence

$\circ$ Gardner's multiple intelligences

$\circ$ Emotional intelligence

Intelligence tests

- Stanford-Binet Intelligence Test

- Wechsler intelligence tests

- Matrix tests (Raven's matrices, Naglieri Nonverbal Intelligence Test, Universal Intelligence Test, etc.)

- Test bias

- Spearman's "indifference of the indicator"

- Development of early intelligence tests (Galton through the 1920's)

Intelligence and the brain

- Studies of brain size or structure (e.g., white matter to grey matter ratio, frontal lobe size) and intelligence

- Studies of reaction time and intelligence

- Studies of live brain functioning (e.g., fMRI, PET, EEG) and intelligence

- Parieto-Frontal Integration Theory (P-FIT)

Cognitive processes

- Working memory

- Short-term memory

- Spatial ability/reasoning

- Verbal ability

- Fluid \& crystallized intelligence

- Relationship between crystallized and fluid intelligence

- Visual perception

- Mental maps of three-dimensional space

- Spearman's law of diminishing returns

Genetics and heritability of intelligence

- Twin studies

- Family studies

- Genome-wide association studies (GWAS)

- Adoption studies

Environmental effects on intelligence

- Prenatal exposure to toxins (e.g., alcohol, cigarette smoke, heavy metals)

- Birth order effects

- Lead poisoning

- Famine and extreme malnutrition

- Deprivation and neglect 
- Influence of parenting

- Interventions to raise IQ in normal populations (e.g., preschool, special educational programs)

- Childhood environment (e.g., parenting, early childhood education)

Social impacts

- Intelligence and educational attainment (e.g., GPA, test scores, degrees earned)

- Intelligence and learning speed

- Intelligence and job training

- Intelligence and job performance

- Studies of intelligence in military populations

- Hiring and promoting decisions and intelligence

- Intelligence and health disparities

- Intelligence and life expectancy

- Intelligence and crime/delinquency

Correlations with other variables

- Jensen effects

- Intelligence and creativity

- Big Five personality traits and intelligence

- Intelligence and mental health

Long-term trends:

- Human evolution and intelligence

- Flynn effect

- Dysgenic effects

- Assortative mating for intelligence and/or education

Development and aging process:

- Measuring intelligence in young children $(\leq 4$ years)

- Relationship between IQ and Piaget's stages of cognitive development

- Longitudinal studies of cognitive abilities

- Interventions to slow or reverse cognitive decline in old age

Demographic differences:

- Differing variability of intelligence and other mental abilities across sexes

- Sex differences in Stratum I and Stratum II abilities

- Size of racial differences in intelligence and/or Stratum II abilities

- Are Black-White mean intelligence differences narrower today than in the past?

- Spearman's hypothesis

- Causes of within-group differences in intelligence

- Causes of between-group differences in intelligence

- Evolutionary psychology theories of causes of group differences in mental abilities

- Cross-cultural validity of intelligence (as a construct) and/or intelligence tests Societal implications:

- National IQ averages and economic development

- The welfare state and individual differences in ability

- Implications of individual intelligence differences for the education system

- Achieving proportionality of demographic groups in different careers (e.g., STEM)

- Intelligence and affirmative action

- Intelligence and immigration policy 
- Lifelong economic mobility and intelligence

- Cross-generational economic mobility and intelligence

Longitudinal studies:

- Lewis Terman's Genetic Studies of Genius

- Scottish Mental Surveys

- Seattle Longitudinal Studies

- Study of Mathematically Precocious Youth (SMPY)

History of intelligence research

- Intelligence researchers and the early 20th century eugenics movement

- The Bell Curve (book by Herrnstein and Murray)

- The Mismeasure of Man (book by Stephen Jay Gould)

- Did Sir Cyril Burt commit research fraud?

- Life and work of important scientists (any of these people could be the topic of a paper)

- Sir Francis Galton (1822-1911)

○ Alfred Binet (1857-1911)

○ Charles Spearman (1863-1945)

- Lewis Terman (1877-1956)

○ Louis L. Thurstone (1887-1955)

- David Wechsler (1896-1981)

- Raymond Cattell (1905-1998)

○ John B. Carroll (1916-2003)

○ Arthur Jensen (1923-2012)

○ John L. Horn (1928-2006)

○ James Flynn (1934- )

○ Linda Gottfredson (1947- )

○ Ian Deary (1954- )

Miscellaneous topics:

- Intelligence in animals (e.g., dogs, cats, rats, horses, birds, non-human primates)

- Savants

- Child prodigies

- MENSA International (high IQ society) 
Table A1

Catalog: Intelligence Category frequencies for colleges based on each list in US News Top Schools Report

University $\mathrm{UG}^{\mathrm{a}} \quad \mathrm{G}^{\mathrm{b}}$ Emotional Social Cultural Multiple Generic $g$ Theory Introductory Testing Race Artificial Animal Other Total

$$
\text { Type }
$$

\begin{tabular}{|c|c|c|c|c|c|c|c|c|c|c|c|c|c|c|c|}
\hline National & 312 & 185 & 119 & 9 & 13 & 23 & 153 & 8 & 17 & 94 & 15 & 37 & 16 & 9 & 497 \\
\hline $\begin{array}{l}\text { Liberal Arts } \\
\text { Regional - }\end{array}$ & 117 & 5 & 12 & 6 & 1 & 5 & 42 & 3 & 13 & 20 & 4 & 16 & 5 & 3 & 122 \\
\hline $\begin{array}{l}\text { Midwest } \\
\text { Regional - }\end{array}$ & 45 & 42 & 22 & 3 & 6 & 10 & 11 & 0 & 3 & 27 & 0 & 0 & 2 & 3 & 87 \\
\hline $\begin{array}{l}\text { North } \\
\text { Regional - }\end{array}$ & 49 & 26 & 15 & 6 & 0 & 5 & 18 & 1 & 0 & 26 & 0 & 4 & 1 & 0 & 75 \\
\hline $\begin{array}{l}\text { South } \\
\text { Regional - }\end{array}$ & 37 & 14 & 9 & 3 & 1 & 2 & 12 & 0 & 2 & 19 & 0 & 1 & 0 & 2 & 51 \\
\hline West & 37 & 24 & 18 & 1 & 0 & 2 & 18 & 0 & 5 & 14 & 0 & 1 & 0 & 2 & 61 \\
\hline Total & 597 & 296 & 195 & 28 & 21 & 47 & 254 & 12 & 40 & 200 & 19 & 59 & 24 & 19 & 893 \\
\hline
\end{tabular}

${ }^{\mathrm{a} U G}=$ Undergraduate. ${ }^{\mathrm{b}} \mathrm{G}=$ Graduate 
Table A2

Catalog - Intelligence Type based on University Ranking List

\begin{tabular}{|c|c|c|c|c|c|c|c|c|c|c|c|c|}
\hline Univeristy Type & $\mathrm{UG}^{\mathrm{a}}$ & $\mathrm{G}^{\mathrm{b}}$ & Emotional & Social & Cultural & Multiple & Generic & $\begin{array}{l}\text { G- } \\
\text { Theory }\end{array}$ & GeneralPsy & Testing & Race & Artificial \\
\hline National & 312 & 185 & 119 & 9 & 13 & 23 & 153 & 8 & 17 & 94 & 15 & 37 \\
\hline Liberal Arts & 117 & 5 & 12 & 6 & 1 & 5 & 42 & 3 & 13 & 20 & 4 & 16 \\
\hline Regional - & & & & & & & & & & & & \\
\hline Midwest & 45 & 42 & 22 & 3 & 6 & 10 & 11 & 0 & 3 & 27 & 0 & 0 \\
\hline Regional - North & 49 & 26 & 15 & 6 & 0 & 5 & 18 & 1 & 0 & 26 & 0 & 4 \\
\hline Regional - South & 37 & 14 & 9 & 3 & 1 & 2 & 12 & 0 & 2 & 19 & 0 & 1 \\
\hline Regional - West & 37 & 24 & 18 & 1 & 0 & 2 & 18 & 0 & 5 & 14 & 0 & 1 \\
\hline Total & 597 & 296 & 195 & 28 & 21 & 47 & 254 & 12 & 40 & 200 & 19 & 59 \\
\hline
\end{tabular}

${ }^{\mathrm{a}} \mathrm{UG}=$ Undergraduate, ${ }^{\mathrm{b}} \mathrm{G}=$ Graduate 
